\title{
Article \\ Self-Tuning Algorithm for Tuneable Clamping Table for Chatter Suppression in Blade Recontouring
}

\author{
Markel Sanz-Calle ${ }^{1, *(1)}$, Zoltan Dombovari ${ }^{1,2} \oplus$, Jokin Munoa ${ }^{1,3}{ }^{\circ}$, Alexander Iglesias $1 \oplus$ \\ and Luis Norberto López de Lacalle ${ }^{3}$ (D) \\ 1 Dynamics \& Control Department, Ideko, Elgoibar, 20870 Basque Country, Spain; \\ dombovari@mm.bme.hu (Z.D.); jmunoa@ideko.es (J.M.); aiglesias@ideko.es (A.I.) \\ 2 MTA-BME Lendület Machine Tool Vibration Research Group, Department of Applied Mechanics, \\ Budapest University of Technology and Economics, Muegyetem rkp. 3, H1111 Budapest, Hungary \\ 3 Mechanical Engineering Department, Faculty of Engineering of Bilbao, University of the Basque Country, \\ 48013 Bilbao, Spain; norberto.lzlacalle@ehu.eus \\ * Correspondence: msanz@ideko.es
}

Citation: Sanz-Calle, M.; Dombovari, Z.; Munoa, J.; Iglesias, A.; López de Lacalle, L.N. Self-Tuning Algorithm for Tuneable Clamping Table for Chatter Suppression in Blade Recontouring. Appl. Sci. 2021, 11 2569. https://doi.org/10.3390/ app11062569

Academic Editor: Paolo Neri

Received: 18 February 2021

Accepted: 12 March 2021

Published: 13 March 2021

Publisher's Note: MDPI stays neutral with regard to jurisdictional claims in published maps and institutional affiliations.

Copyright: (c) 2021 by the authors. Licensee MDPI, Basel, Switzerland. This article is an open access article distributed under the terms and conditions of the Creative Commons Attribution (CC BY) license (https:/ / creativecommons.org/licenses/by/ $4.0 /)$.

\begin{abstract}
The production and repair of blades for aerospace engines and energy turbines is a complex process due their inherently low stiffness and damping properties. The final recontouring operation is usually performed by milling operations where regenerative chatter is one of the main productivity limiting factors. With the objective of avoiding specific stiffening fixtures for each blade geometry, this paper proposes a semi-active tuneable clamping table (TCT) based on mode tuning for blade machining. The active mode of the device can be externally controlled by means of a rotary spring and eddy current damping modules. Its in-series architecture allows damping to be introduced to the critical mode of the thin-walled part without any direct contact in the machining area and enables a more universal clamping. Its chatter suppression capabilities are maximized by means of a novel self-tuning algorithm that iteratively optimizes the tuning for the measured chatter frequency. The benefits of the iterative algorithm are validated through semidiscretization and initial value time-domain simulations, showing a clear improvement in blade recontouring stability compared to regular broad-bandwidth tuning methods.
\end{abstract}

Keywords: blades; milling; chatter; damping; fixture

\section{Introduction}

The manufacturing and repair of fan, compressor and turbine blades constitute very high added-value industrial processes with a high relevance in the aerospace manufacturing industry. Due to the continuous increase in raw material and manufacturing costs, the specific weight of maintenance, repair and overhaul (MRO [1,2]) processes of engine parts has been increasing in recent years, which in some applications can result in savings of up to $70 \%$ of the total costs compared to disposal and replacement with a remanufactured component [3].

Among the four main stages of the blade repair process (pre-inspection, welding, machining and post-inspection [4]), the machining or recontouring stage is of particular interest due to the specific problems that arise during these operations. The aim of the recontouring stage is to remove, by machining operations, the excess material added in the welding stage (see Figure $1 \mathrm{a}, \mathrm{b}$ ) using additive manufacturing technologies such as laser cladding [5] or laser metal deposition [6] and achieve the final blade geometry. Although these operations have traditionally been performed through manual belt grinding, the need to automate the process to the extent possible has encouraged the engine part maintenance industry to move towards milling-based recontouring (see Figure 1c), performed on 5-axis machines or hybrid cells in which welding and machining operations are performed in the same clamping $[7,8]$. 
In any case, milling operations on thin-walled blades are always a complicated task due to static deflections and, especially, the occurrence of regenerative chatter. The inherently low stiffness and damping properties of the thin-walled blades result in a large dynamic flexibility at the points to be recontoured and largely promote the onset of chatter. Chatter is a type of self-excited vibration caused by the regenerative effect, whereby each cutting edge cuts the wavy pattern left by the vibration in the previous pass $[9,10]$. Under certain cutting parameters, this closed-loop relationship can become unstable and result in deep surface marks that can lead to rejection of the machined blade, accelerated tool wear and damage to machine tool components.

Chatter suppression can be tackled in different ways [11], such as spindle speed tuning based on a stability lobe diagram (SLD), optimized tool geometries [12] or continuous spindle speed variation [13]. However, the difficult-to-cut titanium, nickel and cobalt alloys commonly used for the blades and the uneven and varying dynamics of blades greatly restrict the applicability of process parameter tuning techniques. The optimization of tool or process parameters may not be effective when the dynamics of the part are altered, or a severe decrease in tool life may occur if the spindle speed is outside the narrow recommended cutting speed range. Increasing the dynamic stiffness of the blade by means of stiffening devices or dampers provides a different approach to reduce the tendency to regenerative chatter without actually changing the process parameters.
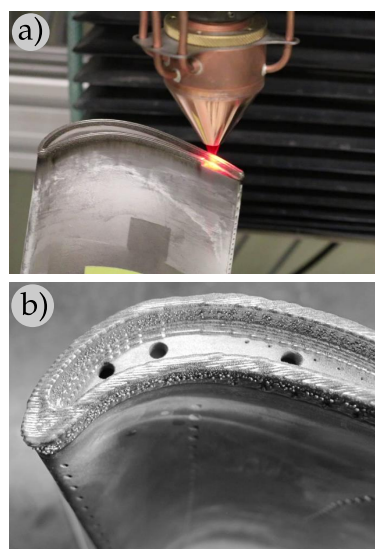

c)
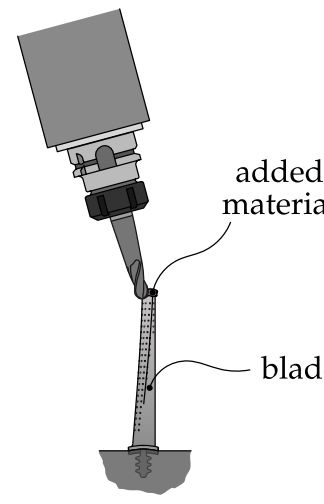

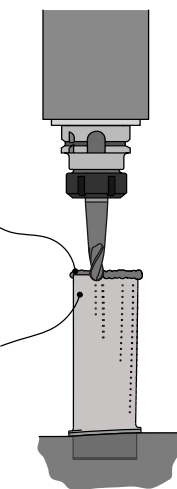

d)

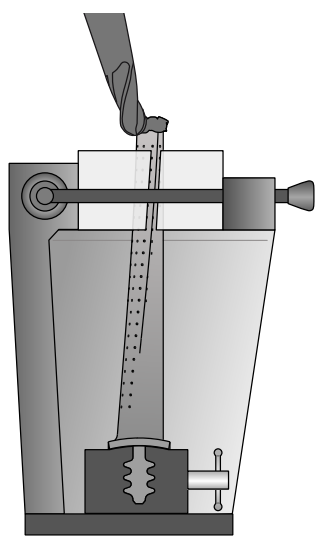

Figure 1. Blade repairing process. (a) Laser metal deposition for blade tip repair [6]. (b) Excess of material to be removed [6]. (c) Recontouring by means of 5-axis milling. (d) Clamping fixture for blade recontouring operations.

The application of stiffening devices based on the clamping of the blade near the tip (see Figure 1d) is the most widespread technique at industrial level to prevent chatter in blade MRO processes. To cope with different blade geometries and dimensions, a wide set of fixtures is required, which must also have a certain level of flexibility to cope with the shape deviation of the damaged blade and not to cause an excessive static deflection. In this regard, the use of low melting point alloys as pinpoint has also been investigated as a more flexible stiffening alternative [14].

On the other hand, active and passive dampers can also be implemented to increase the dynamic stiffness of the blades. Active dampers can improve the dynamic stiffness of the part by counteracting the measured vibration by means of an actuator. This idea has recently been implemented to successfully damp flexible parts during heavy duty milling operations on thin walls [15]. Besides, passive damping solutions in the form of tuned mass dampers (TMDs) [16] or Lanchester dampers [17], have lately been applied for chatter avoidance in blade and similar thin-walled part milling. Nevertheless, the application of the technologies developed so far to blade recontouring may not be feasible, as they require direct attachment of the device close to the machining point, which may interfere with the machining trajectory or pose a major difficulty when dealing with blades with complex geometries. 
As opposed to the in-parallel architecture of regular TMDs, the tuneable clamping table (TCT [18]) is an application case of mode tuning with an in-series architecture, which can increase the damping of the critical mode by tuning a highly damped and controlled mode close to the targeted mode in the frequency band. Its in-series architecture provides the capability to achieve the tuning between the controlled mode and the critical mode of the blade with a universal clamping system and without any direct intervention in the cutting zone.

Nevertheless, in mode tuning devices fine tuning is essential to achieve a maximum increase in dynamic stiffness. To this effect, the algebraic expressions for optimal $H_{\infty}$ tuning for a TCT have already been developed [18], which are the equivalent-but different- to classical TMD amplitude tuning methodologies $[19,20]$. When the aim is to maximize milling stability, the aforementioned strategies are no longer optimal [21], and specific tuning procedures based on the optimization of the real part of the receptance function have to be applied [22,23]. In any case, whatever the objective function, the aim of these strategies is to achieve a wide-bandwidth tuning, considering that neither the part dynamics nor the frequency of the external excitation are subject to change during normal operation.

In an industrial environment where a wide variety of parts - and therefore, dynamicsexists and therefore a high degree flexibility and automation is sought, the TCT provides a blade clamping solution to mitigate chatter vibrations with a universal clamping system and minimal interference with the cutting process. This paper presents a self-tuning algorithm for the tuneable clamping table for efficient blade manufacturing and repair. Benefiting from the possibility of externally tuning the frequency and damping of its active mode, its iterative nature allows the device's chatter suppressing capability to be exploited to the maximum extent and also provides the capacity to adapt to blades with uneven dynamics. The analytical expressions for iterative tuning are introduced, which are implemented in an algorithm running in real-time during the milling process. The algorithm is then validated through semidiscretization and initial value time-domain simulations, showing a superior performance compared to regular wide-bandwidth tuning methods.

\section{Semi-Active Tuneable Clamping Table: Concept and Benefits}

Similarly to TMDs, the tuneable clamping table proposed for blade recontouring is based on mode tuning. When tuning the controlled mode close in the frequency band to the lowly-damped critical mode of the blade, the two modes interact and the shapes of the neighboring modes are combined. Due to the existence of the damping of the device, a partial transfer of damping between the ideal (stand-alone) modes is achieved, which can be used to increase the dynamic stiffness of the system.

Nevertheless, the classical TMD and TCT concepts present significant differences. Figure 2 shows the differences in architecture between the well-known tuned mass damper and the tuneable clamping table. As opposed to the TMDs, where the controlled mode is placed in-parallel to the excitation force flow (Figure 2a), the TCT approach adopts an in-series configuration (Figure 2b), clamping the blade from below. In this way, mode tuning and the subsequent increase of the dynamic stiffness at the machining point can be achieved without physically attaching any device to the blade near the machining zone that could interfere with the cutting process. Moreover, this permits the development of a universal clamping system for the entire blade set without the need for an array composed by specific fixtures or dampers for every blade geometry.

In order to cope with a wide set of blades with different dynamics, the TCT concept is implemented in a semi-active form in this paper. Semi-active damping devices, first introduced in [24] for chatter suppression, require external energy to achieve the tuning, but unlike active devices, the dissipation of vibration energy takes place without any external energy input. The alteration of the stiffness, damping or mass properties of the device mode can be achieved by multiple means. Purely mechanical assemblies based on preloaded elastomers [24], position-adjustable moving masses [25,26] or rotary springs [27-30] have been proposed to control the stiffness of the damper. Regarding the 
damping, eddy current modules have been proven to be a reliable alternative for obtaining a nearly-ideal and adjustable viscous damping $[18,28,29]$. The use of electrorheological and magnetorheological fluids to simultaneously control the stiffness and damping of the device has also been investigated [31], with application over vibration attenuation in thin walled part milling as well [32,33]. Finally, it is also worth mentioning the use of piezoelectric shunts for semi-active damping purposes [34-36].

a)

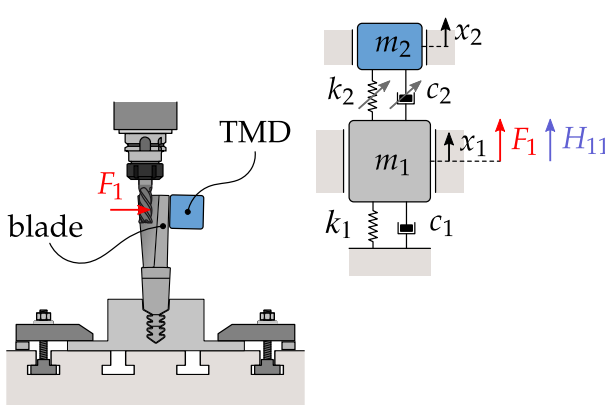

b)

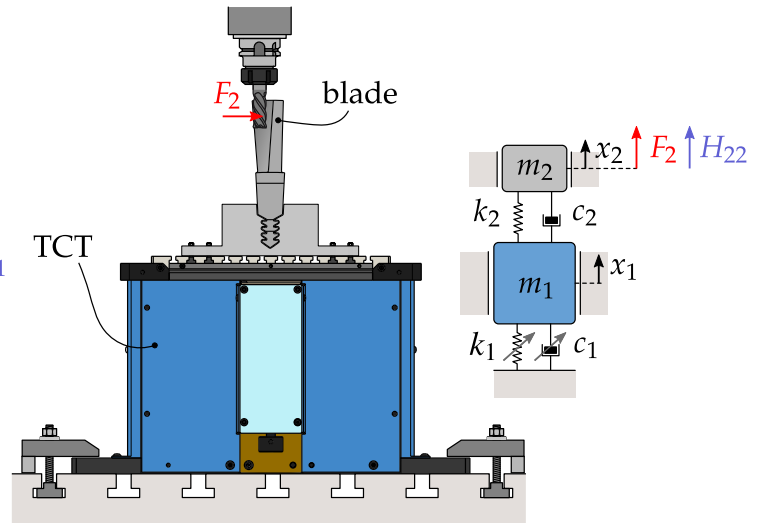

Figure 2. Passive damping concepts based on mode tuning for blade manufacturing and repair and their associated 2-degree of freedom (DoF) lumped-mass models. (a) Traditional tuned mass damper (TMD). (b) Tuneable clamping table (TCT).

Indeed, regardless of how the mode is controlled, semi-active devices require a control strategy to achieve the tuning of the device mode to the critical mode to be damped. In this sense, velocity [34] or force [37] feedback control strategies, as well as fuzzy control algorithms [38,39], can be found in the literature. Nonetheless, when it comes to suppressing regenerative chatter - rather than general vibration problems-iterative algorithms based on the measured chatter frequency show a higher degree of effectiveness [29,40].

In the case of the semi-active TCT presented here, the controlled mode is materialized as a dominant translational mode with a fixed moving mass $m_{1}$ guided by flexures of stiffness $k_{\mathrm{f}}$. The table features a rotary spring (see Figure 3) with unequal stiffnesses $k_{\mathrm{s}, 1}$ and $k_{\mathrm{s}, 2}$ in its two main directions and driven by a motor-encoder assembly. This permits externally modifying the stiffness $k_{1}$ and, consequently, the natural frequency $\omega_{1}$ of the device with the angular position of the spring $\theta$ as

$$
k_{1}^{-1}=k_{\mathrm{f}}^{-1}+\left(k_{\mathrm{s}, 1} \cos ^{2} \theta+k_{\mathrm{s}, 2} \sin ^{2} \theta\right)^{-1} .
$$

In this manner, blade modes within the frequency range $\left[\omega_{1, \min }, \omega_{1, \max }\right]$, as shown in Figure 3, can be tuned with the TCT. The viscous damping of the table is provided by the eddy current damping modules under the table, whose damping level can be adjusted by modifying the immersion of the conductive plates inside the magnetic field created by permanent magnets. Further details on its mechanical design and conception can be found in [18].

Finally, once the design and construction of the TCT has been defined, the objective is to develop a control strategy seeking for the maximization the chatter suppression capabilities of the TCT. Similar to the aforementioned strategies for TMDs [29,40], an iterative self-tuning algorithm for the in-series architecture based on the measured chatter frequency is proposed here. The development and implementation of said algorithm is explained in the following sections. 

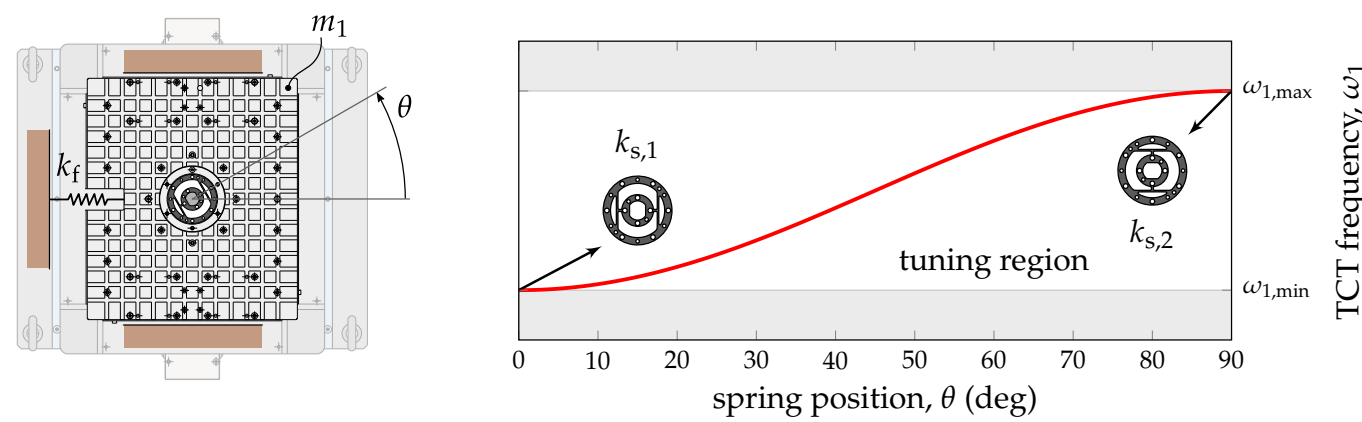

Figure 3. Frequency tuning of the TCT by means of the angular position $\theta$ of the rotary spring.

\section{Unidirectional Milling Model with Tuneable Clamping Table}

Tip recontouring processes mostly consist of one or several milling passes parallel to the so-called chord line of the blade. Like many other parts with thin wall characteristics, blades usually present a dominant modal direction normal to the chord line and perpendicular to the feed motion of the cutter, along which the active direction of the TCT is placed for maximum efficiency of the mode tuning. Accordingly, the whole milling dynamics can be accurately described in this case by a unidirectional milling model as in Figure 4.

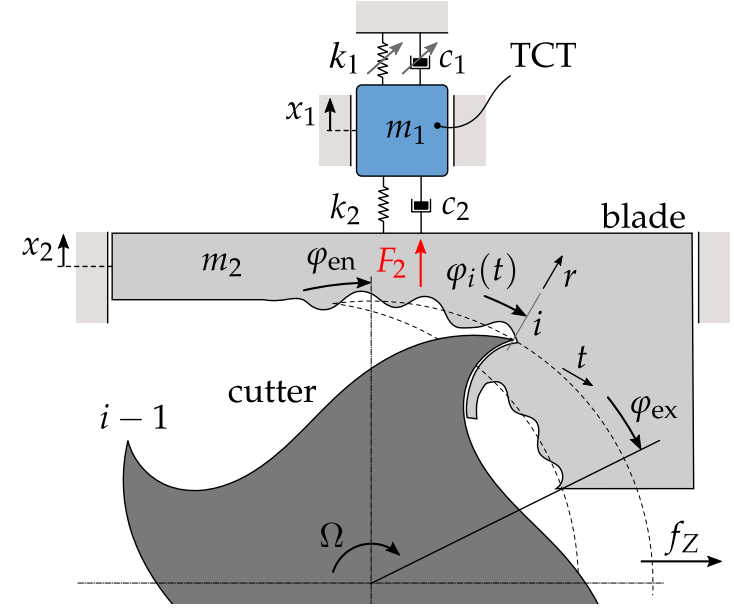

Figure 4. Regenerative planar milling model with the tuneable clamping table.

\subsection{Structural Dynamics}

Similarly to other thin-walled parts, the presence of very lowly-damped modes that are well-separated over the frequency band is usually expected, which results in a negligible level of coupling between the different blade modes. Under these circumstances, the dynamic behavior of the blade at the machining point nearby a targeted (dominant) mode can be accurately represented by a 2-degree of freedom (DOF) lumped mass model as in Figure $4 . m_{1}, k_{1}$ and $c_{1}$ represent the standalone active mode of the device and $m_{2}, k_{2}$ and $c_{2}$ define the standalone targeted mode of the blade at the machining point, leading to

$$
\mathbf{M} \ddot{\mathbf{x}}(t)+\mathbf{C} \dot{\mathbf{x}}(t)+\mathbf{K} \mathbf{x}(t)=\mathbf{F}(t),
$$

where

$$
\begin{aligned}
& \mathbf{M}=\left[\begin{array}{cc}
m_{1} & 0 \\
0 & m_{2}
\end{array}\right], \mathbf{C}=\left[\begin{array}{cc}
c_{1}+c_{2} & -c_{2} \\
-c_{2} & c_{2}
\end{array}\right], \\
& \mathbf{K}=\left[\begin{array}{cc}
k_{1}+k_{2} & -k_{2} \\
-k_{2} & k_{2}
\end{array}\right], \mathbf{x}=\left[\begin{array}{l}
x_{1}(t) \\
x_{2}(t)
\end{array}\right] \text { and } \mathbf{F}=\left[\begin{array}{c}
0 \\
F_{2}(t)
\end{array}\right] .
\end{aligned}
$$




\subsection{Regenerative Milling Force}

For simplicity, a cylindrical and straight fluted end mill with $Z$ regularly spaced teeth rotating at a constant spindle speed $\Omega$ is considered. Assuming a cutting force model with linear characteristics with respect to the chip thickness $h$, the specific cutting force vector $\mathbf{f}=\mathbf{F} / a$ in the tangential-radial plane $(t, r)$ can be defined as

$$
\mathbf{f}_{t r, i}(t)=-\left(\mathbf{K}_{\mathrm{e}}+\mathbf{K}_{\mathrm{c}} h_{i}(t)\right),
$$

where $\mathbf{K}_{\mathrm{e}}=\left[K_{t e}, K_{r \mathrm{e}}\right]^{\top}$ and $\mathbf{K}_{\mathrm{c}}=\left[K_{t c}, K_{r \mathrm{c}}\right]^{\top}$ are respectively the so-called edge and cutting coefficient vectors resulting from the linear fitting to the experimentally measured mean cutting forces [41]. Due to the regenerative effect, each cutting edge cuts the wavy surface left by the vibration of the previous tooth. Hence, the momentary chip thickness can be calculated by approximating the tool edge kinematics to a circular motion as

$$
h_{i}(t) \approx\left(f_{Z} \sin \varphi_{i}(t)+\left(\left(x_{2}(t)-x_{2}(t-\tau)\right) \cos \varphi_{i}(t)\right),\right.
$$

where $\tau$ is the regenerative delay, which is equal to the tooth passing period $T_{Z}=\frac{2 \pi}{Z \Omega}$ in this case, and where

$$
\varphi_{i}(t)=\Omega t+2 \pi \frac{i-1}{Z}
$$

stands for the angular position of the $i$ th tooth at the instant $t$. The total cutting force $F_{2}$ to which the blade is subjected to for an axial depth of cut $a$ can be hence calculated by summing the projections onto the flexible direction of all the $Z$ teeth as

$$
F_{2}(t)=-a \sum_{i=1}^{Z} g\left(\varphi_{i}(t)\right)\left(\left(K_{t \mathrm{e}}+K_{t \mathrm{c}} h_{i}(t)\right) \sin \varphi_{i}(t)-\left(K_{r \mathrm{e}}+K_{r \mathrm{c}} h_{i}(t)\right) \cos \varphi_{i}(t)\right),
$$

where $g(\varphi)$ represents the screen function

$$
g(\varphi)= \begin{cases}1, & \text { if } \varphi_{\mathrm{en}}<\varphi \bmod 2 \pi<\varphi_{\mathrm{ex}} \\ 0, & \text { otherwise, }\end{cases}
$$

which determines whether the tooth is in or out of cut.

The total cutting force can be divided into two terms as $F_{2}(t):=F_{2}\left(t, x_{2}(t), x_{2}(t-\right.$ $\tau))=G(t)+\Delta F\left(t, x_{2}(t), x_{2}(t-\tau)\right)$. The former is the time-periodic stationary forcing term

$$
\begin{array}{r}
G(t) \equiv G\left(t+T_{Z}\right)=-a \sum_{i=1}^{Z} g\left(\varphi_{i}(t)\right)\left(\left(K_{t \mathrm{e}}+K_{t \mathrm{c}} f_{Z} \sin \varphi_{i}(t)\right) \sin \varphi_{i}(t)\right. \\
\left.-\left(K_{r \mathrm{re}}+K_{r \mathrm{c}} f_{\mathrm{Z}} \sin \varphi_{i}(t)\right) \cos \varphi_{i}(t)\right),
\end{array}
$$

which represents the cutting forces of the equivalent undeformed milling model. This term induces an unavoidable forced vibration $\mathbf{x}_{\mathbf{s}}(t)$. The latter is the state-dependent variational term of the cutting force. It arises due to the regenerative nature of the cutting force and is calculated as

$$
\Delta F\left(t, x_{2}(t), x_{2}(t-\tau)\right)=-a K_{t c} B(t)\left(\left(x_{2}(t)-x_{2}(t-\tau)\right),\right.
$$

where

$$
\begin{aligned}
B(t)= & B\left(t+T_{Z}\right):= \\
& \sum_{i=1}^{Z} g\left(\varphi_{i}(t)\right)\left(\frac{K_{r \mathrm{c}}}{K_{t \mathrm{c}}} \cos ^{2} \varphi_{i}(t)-\sin \varphi_{i}(t) \cos \varphi_{i}(t)\right)=\sum_{i=1}^{Z} g\left(\varphi_{i}\right) b\left(\varphi_{i}\right)
\end{aligned}
$$


is the time-periodic directional milling coefficient, which concentrates the projection of the cutting force onto the mode direction and the projection of the vibration onto the chip thickness direction.

The presence of the regenerative- or dynamic — term of the cutting force makes the governing equation a time-periodic delay differential equation (DDE [42]). Under a certain set of cutting parameters, the DDE can undergo Hopf or period-doubling (flip) instabilities, which actually correspond to the large amplitude chatter vibrations.

\subsection{Zeroth-Order Milling Stability}

The asymptotic linear stability of the stationary solution of (2) can be assessed by introducing a perturbation $\mathbf{p}(t)$ around the stationary solution $\mathbf{x}(t)=\mathbf{x}_{\mathbf{S}}(t)+\mathbf{p}(t)$. For the case that the perturbed solution $\mathbf{p}(t)$ is not influenced by the stationary cutting solution, the stability of (2) can be evaluated by studying the stability of the perturbed equation:

$$
\mathbf{M} \ddot{\mathbf{p}}(t)+\mathbf{C} \dot{\mathbf{p}}(t)+\mathbf{K} \mathbf{p}(t)=\Delta \mathbf{F}\left(t, p_{2}(t), p_{2}(t-\tau)\right) .
$$

Numerical methods such as semidiscretization [43] or full-discretization [44] are wellestablished and efficient techniques for assessing the stability properties of time-periodic DDEs. However, like other numerical methods, they often hide the direct relations between process parameters and system stability that could serve as a core function for a stability maximization algorithm. Instead, the stability of (12) can be studied in the frequency domain by considering the marginal case where the system has a critical dominant vibration (chatter) frequency $\omega_{\mathrm{c}}$ and its modulations $\omega_{\mathrm{c}}+k \omega_{Z}$ related to the tooth passing frequency $\omega_{Z}=2 \pi / T_{Z}$ as

$$
\mathbf{p}(t)=\sum_{k=-\infty}^{\infty} \mathbf{p}_{k} \mathrm{e}^{\mathrm{i}\left(\omega_{\mathrm{c}}+k \omega_{\mathrm{Z}}\right) t},
$$

together with the Fourier decomposition of the time-periodic milling coefficient

$$
B(t)=\sum_{k=-\infty}^{\infty} B_{k} \mathrm{e}^{\mathrm{i} k \omega_{Z} t}:=\frac{Z}{2 \pi} \sum_{k=-\infty}^{\infty} \beta_{k} \mathrm{e}^{\mathrm{i} k \omega_{Z} t}, \quad \text { where } \quad \beta_{k}=\int_{\varphi_{\mathrm{en}}}^{\varphi_{\mathrm{ex}}} b(\varphi) \mathrm{e}^{\mathrm{i} k Z \varphi} \mathrm{d} \varphi .
$$

In case of only being interested in Hopf-type instabilities, (13) can be truncated to $k=0$ and the directional milling coefficient approximated by is averaged value $B(t) \approx$ $B_{0}:=\frac{Z}{2 \pi} \beta_{0}$, where

$$
\beta_{0}=\int_{\varphi_{\mathrm{en}}}^{\varphi_{\mathrm{ex}}} b(\varphi) \mathrm{d} \varphi=\frac{1}{4}\left[\cos 2 \varphi+\frac{K_{r \mathrm{c}}}{K_{t \mathrm{c}}}(2 \varphi+\sin 2 \varphi)\right]_{\varphi_{\mathrm{en}}}^{\varphi_{\mathrm{ex}}}
$$

is the mean directional factor [45]. This approximation-commonly known as the zerothorder algorithm (ZOA [46]) - leads to an eigenvalue problem from which the critical stability curves can be parametrically computed. ZOA provides accurate results in noninterrupted milling processes where only Hopf bifurcations are expected and the effect of machining mode coupling is negligible [47].

In a unidirectional milling case like this, the eigenvalue problem is reduced to the following scalar characteristic equation:

$$
p_{2,0}=a K_{t c} \beta_{0} \frac{Z}{2 \pi} H_{22}\left(\omega_{c}\right)\left(\mathrm{e}^{-\mathrm{i} \omega_{\mathrm{c}} \tau}-1\right) p_{2,0},
$$

where $H_{22}$ refers to the direct receptance function at the blade tip originated from

$$
\mathbf{H}(\omega)=\left(-\omega^{2} \mathbf{M}+\mathrm{i} \omega \mathbf{C}+\mathbf{K}\right)^{-1}=\left[H_{i, j}(\omega)\right], \text { where } i, j=1,2 .
$$


In this way, a semi-analytical expression of the parametric root crossing $\left(\Omega_{l}\left(\omega_{\mathrm{c}}\right)\right.$, $\left.a\left(\omega_{\mathrm{c}}\right)\right)$ curves can be raised as

$$
a\left(\omega_{\mathrm{c}}\right)=-\frac{2 \pi}{Z K_{t \mathrm{c}} \beta_{0} \operatorname{Re}\left(H_{22}\left(\omega_{\mathrm{c}}\right)\right)} \quad \text { and } \quad \Omega_{l}\left(\omega_{\mathrm{c}}\right)=\frac{2 \pi}{Z\left(2 \psi_{22}\left(\omega_{\mathrm{c}}\right)+(2 l+3) \pi\right)},
$$

where $l=1,2,3, \ldots$ stands for the lobe number and $\operatorname{Re} H_{22}$ and $\psi_{22}$ are, respectively, the real part and phase of the aforementioned direct receptance function at the blade tip.

\subsection{Semidiscretization Based Milling Stability}

Alternatively to ZOA, the stability of the time-periodic DDE in (12) can be studied by means of time-discrete methods such as semidiscretization. Through the application of the Floquet theory, the semidiscretization method provides the finite-dimensional version of the monodromy matrix [48] for discrete values of $\Omega$ and $a$, whose eigenvalues-Floquet multipliers-are used as a measure of the system stability. If all characteristic multipliers remain inside the unit circle (modulus less than one), then the stationary solution is asymptotically stable, otherwise, it is unstable. In this manner, by setting a fine mesh of $a$ and $\Omega$ pairs, stability maps of highly interrupted milling cases exhibiting Hopf and period doubling instabilities can be constructed.

\section{Chatter Suppressing Strategy for the TCT Architecture}

In the previous section, the semi-analytical expressions relating the system dynamics and milling stability for a blade recontouring case with unidirectional dynamics have been introduced. Taking this relation into account, the objective of the present section is to develop a tuning strategy for the tuneable clamping table to get the most out of the mode tuning for maximum milling chatter suppression.

\subsection{Dimensionless Formulation of the System Dynamics}

As observed in (18), in milling processes with a dominant flexible direction, the limiting depth of cut without chatter is approximately given by the inverse of the oriented receptance function $\beta_{0} \operatorname{Re} H_{22}$ [21]. Therefore, the mean directional factor $\beta_{0}$ determines whether the negative real part of $H_{22}$ (positive directional factor, $\beta_{0}>0$ ) or the positive real part (negative directional factor, $\beta_{0}<0$ ) describes the limiting depth of cut curves. In milling $\beta_{0}$ is most likely to be positive, although negative cases are also possible depending on the radial engagement limits $\left[\varphi_{\mathrm{en}}, \varphi_{\mathrm{ex}}\right]$.

In any case, the complex receptance function of the TCT-blade assembly at the machining point $H_{22}$ can be expressed as a function of the lumped-mass parameters of the 2-DoF system in Figure 4 as

$$
H_{22}(\omega)=\frac{k_{1}+k_{2}+c_{1} \mathrm{i} \omega-m_{1} \omega^{2}}{\left(k_{2}-m_{2} \omega^{2}\right)\left(k_{1}+k_{2}-m_{1} \omega^{2}\right)-k_{2}^{2}+c_{1}\left(k_{2}-m_{2} \omega^{2}\right) \mathrm{i} \omega} .
$$

As can be noticed, the internal viscous damping of the blade $c_{2}$ has been neglected, which leads to a good approximation due to the inherently low damping properties of thin-walled parts. In order to obtain a general tuning formulation for whatever mass and stiffness of both TCT and blade, the receptance function in (19) is transformed into its complex dimensionless form

$$
h_{22}:=h_{22}(g) \equiv H_{22}\left(\omega_{2} g\right) k_{2}=\frac{g^{2}-f^{2}-\mu-2 f \zeta_{1} \mathrm{i} g}{\left(f^{2}-g^{2}\right)\left(g^{2}-1\right)+\mu g^{2}+2 f \zeta_{1}\left(g^{2}-1\right) \mathrm{ig}},
$$

through the dimensionless parameters collected in Table 1. Then, the real part of the dimensionless receptance function, which is the one driving the stability limit, can be obtained as follows: 


$$
\operatorname{Re} h_{22}=\frac{\left(g^{2}-f^{2}-\mu\right)\left(\left(f^{2}-g^{2}\right)\left(g^{2}-1\right)+\mu g^{2}\right)-4 f^{2} \zeta_{1}^{2}\left(g^{2}-1\right) g^{2}}{\left(\left(f^{2}-g^{2}\right)\left(g^{2}-1\right)+g^{2} \mu\right)^{2}+4 f^{2} \zeta_{1}^{2}\left(g^{2}-1\right)^{2} g^{2}} .
$$

Table 1. Definition of the dimensionless dynamic and tuning parameters of the structure.

\begin{tabular}{|c|c|c|c|}
\hline \multicolumn{4}{|c|}{ Part/Structure } \\
\hline & nat. frequency & dimless frequency & \\
\hline & $\omega_{2}:=\sqrt{\frac{k_{2}}{m_{2}}}$ & $g:=\frac{\omega}{\omega_{2}}$ & \\
\hline \multicolumn{4}{|c|}{ TCT/Tuning } \\
\hline nat. frequency & frequency ratio & mass ratio & damping ratio \\
\hline$\omega_{1}:=\sqrt{\frac{k_{1}}{m_{1}}}$ & $f:=\frac{\omega_{1}}{\omega_{2}}$ & $\mu=\frac{m_{2}}{m_{1}}$ & $\zeta_{1}=\frac{c_{1}}{2 m_{1} \omega_{1}}$ \\
\hline
\end{tabular}

\subsection{Excitation Frequency Dependent Tuning for the TCT}

At this point, there are different optimization procedures to maximize the negative part of (21) —or minimize its positive part. The traditional approach, in which constant device tuning is provided no matter what the frequency of the external excitation $g$ is, benefits from the presence of three invariant points in (21). In this manner, a wide-bandwidth optimization of either negative or positive real parts can be achieved as follows: first, the two neighbouring invariants of the corresponding side of the curve are matched and, then, a device damping for a zero-tangent at the mentioned invariants is set. The application of this strategy to the TCT architecture leads to the analytical expressions

$$
f_{\mathrm{o}, \pm}=\sqrt{1-\mu \pm \frac{\sqrt{2 \mu}}{2}} \text { and } \zeta_{1, \mathrm{o}, \pm}=\sqrt{\frac{3 \mu}{8}} \sqrt{\frac{\sqrt{2} \pm \sqrt{\mu}}{\sqrt{2} \pm(3-2 \mu) \sqrt{\mu}}},
$$

for constant frequency ratio and device damping tunings, respectively. A more detailed explanation of the procedure for obtaining these expressions can be found in [23].

Constant parameter tuning strategies offer a good solution for fixed dampers or for dampers whose stiffness and damping cannot be externally altered in real-time. However, in semi-active devices like the TCT, the stiffness of the controlled mode can be externally controlled in real-time by means of a rotary spring driven by a motor and an encoder. Therefore, if the frequency of the external excitation $g$ is known, a more efficient tuning strategy based on that frequency can be devised $[29,40]$.

Attending to (18), the arising dominant chatter frequency $\omega_{\mathrm{c}}$ can be considered as sampling on the real part of the receptance function. Thus, a general chatter frequencydependent optimal tuning can be developed by optimising the negative or positive real part of $h_{22}$ for every dimensionless frequency $g=\omega_{\mathrm{c}} / \omega_{2}$. This can be achieved by simply deriving $\operatorname{Re} h_{22}$ with respect to the frequency tuning $f$ and setting it equal to zero as

$$
\begin{aligned}
& \frac{\mathrm{d} \operatorname{Re} h_{22}(g, f)}{\mathrm{d} f}= \\
& \quad \frac{-2 f \mu\left(\left(f^{2}-g^{2}\right)\left(g^{2}-1\right)+g^{2} \mu\right)^{2}+8 f g^{4} \mu \zeta_{1}^{2}\left(g^{2}-1\right)\left(g^{2}-\mu-1\right)}{\left(\left(\left(f^{2}-g^{2}\right)\left(g^{2}-1\right)+g^{2} \mu\right)^{2}+4 f^{2} g^{2} \zeta_{1}^{2}\left(g^{2}-1\right)^{2}\right)^{2}} \equiv 0
\end{aligned}
$$

for every value of the dimensionless frequency $g$ and standalone table damping $\zeta_{1}$. Solving (23) leads to computing five roots: one at $f_{0}=0$ and four others symmetrically arranged with respect to $f_{0}$. By just considering the positive tuning values, the dimensionless (chatter) frequency-dependent tuning formula 


$$
f_{\frac{\mathrm{dRe} h_{22}=0, \pm}{\mathrm{d} f}}(g)=\sqrt{\frac{g^{2}\left(g^{4}+1+\mu-(\mu+2) g^{2} \pm 2 \zeta_{1}^{2} \sqrt{\left(g^{2}-1\right)^{3}\left(g^{2}-1-\mu\right)}\right.}{\left(g^{2}-1\right)^{2}}}
$$

for positive $\left(\beta_{0}>0\right)$ and negative $\left(\beta_{0}<0\right)$ directional factors is attained. The expression (24) presents the tuning limits

$$
g_{\lim ,-}=1 \text { and } g_{\lim ,+}=\sqrt{1+\mu},
$$

outside of which the tuning can actually be applied. When machining close to the resonance of the standalone blade system, dimensionless chatter frequencies close to $g=1$ are expected. This would require an unreachable frequency tuning in practice according to (24), or that may not even exist if $g \in\left[g_{\lim ,-}, g_{\lim ,+}\right]$, which is more likely to occur under a positive directional factor.

Nonetheless, it is important to remember that values of the real part of the receptance higher or lower than zero do not generate lobe structures for positive and negative directional factor cases, respectively. Based on this, an alternative chatter frequency dependent strategy can be devised by simply setting the real part of the receptance function to be zero for every dimensionless chatter frequency, that is,

$$
\begin{aligned}
& \operatorname{Re} h_{22}=0 \rightarrow f_{\text {Re } h_{22}=0}(g)= \\
& \sqrt{\frac{\mu-2 \mu g^{2}-2\left(2 \zeta_{1}^{2}-1\right)\left(g^{2}-1\right) g^{2}+\sqrt{\mu^{2}+8 \zeta_{1}^{2}\left(2(1+\mu) g^{2}-\mu-2 g^{4}+2 \zeta_{1}^{2}\left(g^{2}-1\right)\right)\left(g^{2}-1\right) g^{2}}}{2\left(g^{2}-1\right)}} .
\end{aligned}
$$

Hence, considering that each of the strategies has complementary tuning domains and that for $g>1$ the directional factor must be positive and negative for $g<1$, a frequency dependent tuning strategy can be raised by defining the following piecewise smooth function:

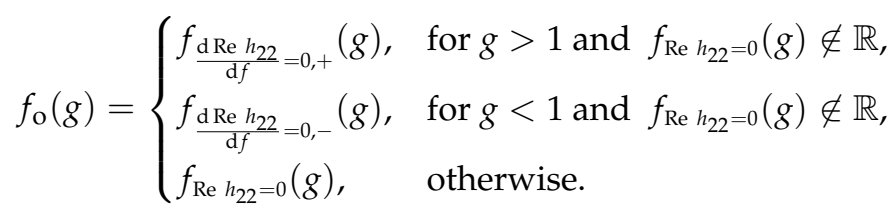

The curves of the optimal frequency tuning ratios depending on the dimensionless frequency are depicted in Figure 5 together with the values of the broad-bandwith (frequency independent) strategies in (22). In practice, the tuning is only realizable in a region limited by $f_{\min }$ and $f_{\max }$ given by the stiffness range limits of the rotary spring (see Figure 3 ).

\subsection{Comparison with Equivalent Constant Parameter Tuning Strategy}

The effect of the proposed tuning strategy can be appreciated by plotting $\operatorname{Re} h_{22}$ optimally tuned for every value of $g$ according to $f_{\mathrm{o}}(g)$ in (27), namely $\operatorname{Re} h_{22}\left(f_{\mathrm{o}}(g), g\right)$, and comparing it to the case with constant tuning $f_{\mathrm{o}, \pm}$ from (22) as in Figure 6a. Here, for comparison purposes, the optimal damping ratios from the corresponding constant tuning strategy in (22) have been set. The excitation frequency dependent strategy further optimizes the wide-bandwidth tuning strategy proposed in [23], except for a single value of $g$ where $f_{\mathrm{o}}(g)$ and $f_{\mathrm{o}, \pm}$ obviously coincide. 


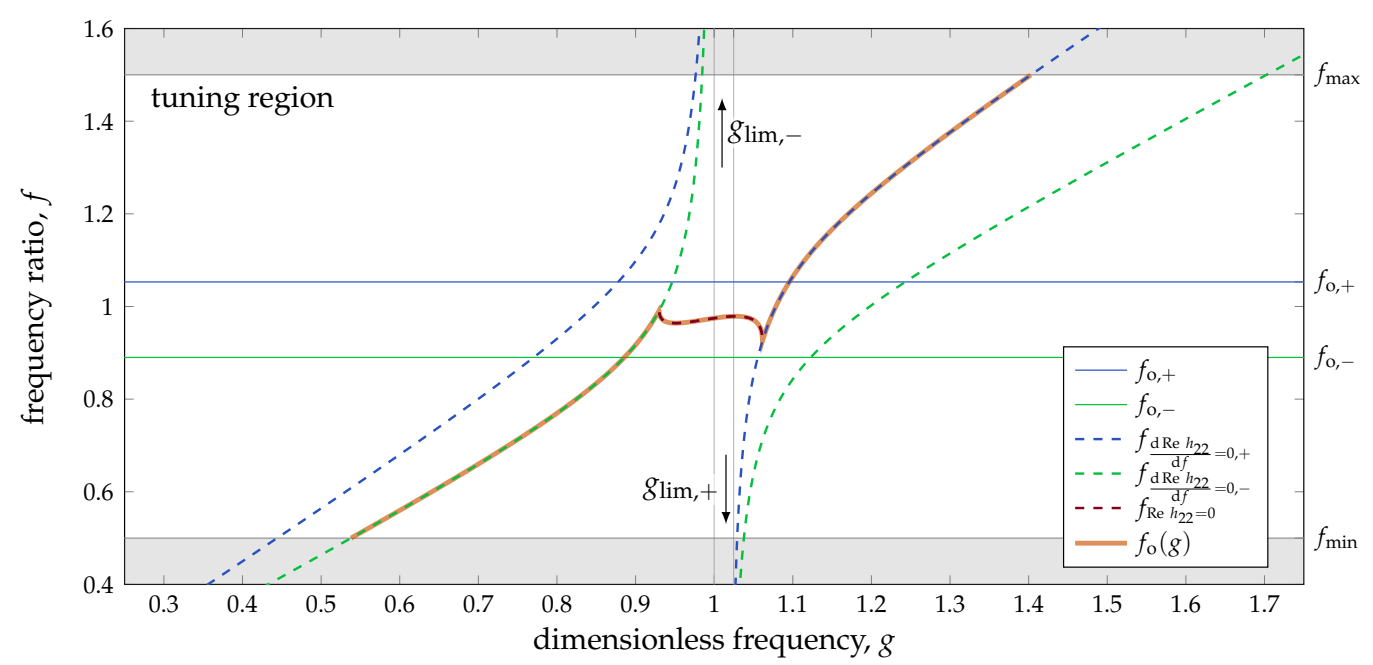

Figure 5. Optimal frequency of the TCT for $\mu=5 \%$ and $\zeta_{1}=10 \%$. The tuning ratio $f$ of the two frequency dependent tunings ( $\frac{\mathrm{d} \operatorname{Re} h_{22}}{\mathrm{~d} f}=0$ and $\operatorname{Re} h_{22}=0$ ) are shown in dashed lines, as well as the combined tuning in the thick orange line. Constant frequency tuning ratios $f_{\mathrm{o}, \pm}$ are also provided in the horizontal thin lines for the sake of comparison.
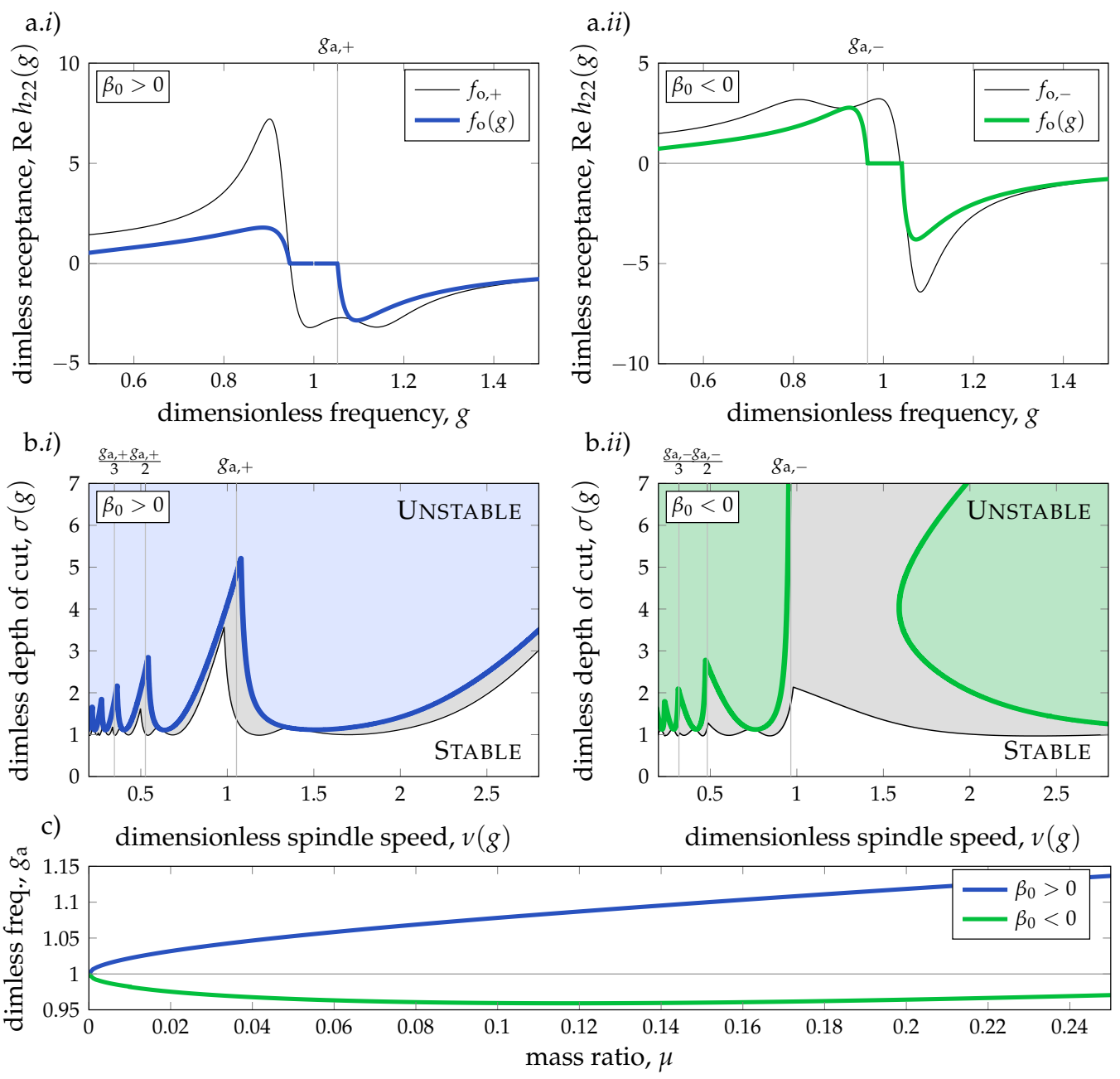

Figure 6. Comparison of the broad-bandwidth tuning and self-tuning strategy for positive and negative directional factor cases. (a) Dimensionless receptance functions. (b) Zeroth order algorithm (ZOA) critical curves. (c) Dimensionless frequencies associated to stability asymptotes. 
The effect of the introduced strategy on the milling stability can be observed by computing stability limit given by the parametric curves of the dimensionless ZOA case as

$$
\sigma(g):=\frac{Z K_{t c} \beta_{0}}{k_{2}} a_{\lim }\left(\omega_{2} g\right)=\frac{2 \pi}{\operatorname{Re} h_{22}(g)} \quad \text { and } \quad v(g):=\frac{Z}{\omega_{2}} \Omega\left(\omega_{2} g\right),
$$

where $\sigma(g)$ and $\nu(g)$ are respectively the dimensionless depth of cut and spindle speed. Figure $6 \mathrm{~b}$ shows the dimensionless stability limits given by the piecewise smooth function $\operatorname{Re} h_{22}\left(f_{\mathrm{o}}(g), g\right)$ and the ones subjected to constant tuning $\operatorname{Re} h_{22}\left(f_{\mathrm{o}, \pm}, g\right)$. As can be observed, the stability is enhanced for both positive and negative directional factor cases over the whole range of spindle speeds, except for the aforementioned points where the two strategies converge. As noticed in [29], the 'double lobe' shape of the stability diagram becomes a 'single lobe' structure.

Finally, apart from the mentioned increase of the stability limit, a variation with respect the location of the maximum stability asymptotes $g_{\mathrm{a}}$ is also noticed. These stability asymptotes are directly linked to the dimensionless spindle speeds at which the so-called 'sweets spots' take place by the relation $v_{\mathrm{a}}=g_{\mathrm{a}} / l$, being $l=1,2,3, \ldots$ the lobe number. These dimensionless resonant frequencies can be numerically computed by simply $\operatorname{Re} h_{22}\left(g_{\mathrm{a}}\right)=0$. The curves of the optimal dimensionless frequency for the frequency dependent strategy presented in this paper are shown in Figure 6c for increasing mass ratio. Accordingly, by implementing the presented tuning and machining at spindle speeds calculated by $g_{a}$, the maximum stability is guaranteed.

\section{Iterative Tuning Algorithm for the TCT}

The excitation frequency dependent tuning strategy leads to a theoretical increase of the stability limits by optimising the system dynamics for each chatter frequency $\omega_{\mathrm{c}}$. Obviously, the direct application of this tuning would imply that the chatter frequency is known beforehand for every value of the spindle speed $\Omega$. In practice, the tuning will only take place once the process is unstable, and for a certain spindle speed $\Omega$ the arising unstable frequency $\omega_{\mathrm{c}}$ will vary with the tuning $f$, since the dynamics of the TCT-blade assembly vary with every tuning. Consequently, the 'final' $\omega_{\mathrm{c}}$ cannot be known in advance. The practical realization of the previously developed tuning strategy must therefore be attained by an algorithm in which the optimal tuning is sought by iteratively measuring the chatter frequency and performing the tuning until the convergence is achieved.

The flowchart of the algorithm proposed for the TCT is shown in Figure 7, which is implemented in a real-time controller. Regardless of the machining parameters, the TCT is initially tuned according to the broad-bandwidth tuning strategy in (22). Once the machining starts, the blade undergoes forced vibration even for the stable cutting situation due to the unavoidable stationary part of (7). The part vibration can be estimated by microphones or other contactless solutions, avoiding sensors that could interfere with the cutting process. Then, the vibration measurement is fed to the real-time controller for the continuous computation of the frequency spectrum. This forced vibration, which manifests itself in the form of harmonics at the tooth passing frequency $\omega_{Z}=2 \pi / T_{Z}$, does not usually entail a real hazard for an acceptable part quality, except in finishing passes where high surface quality is required. When regenerative vibrations arise, a dominant high amplitude peak at a frequency higher or lower than the standalone natural frequency $\omega_{2}$ (for $\beta_{0}>0$ and $\beta_{0}<0$ cases, respectively) can be noticed, leading to deep marks and bad surface quality. 
Therefore, the real-time controller detects the onset of chatter when the frequency of the maximum vibration peak is not an integer of the tooth passing frequency $\omega_{Z}$. If this is the case, the optimal natural frequency of the table $\omega_{1}$ is determined according to the measured chatter frequency $\omega_{\mathrm{c}}$ by setting $\omega_{1}=f_{\mathrm{o}}\left(\omega_{\mathrm{c}} / \omega_{2}\right) \omega_{2}$, with $f_{\mathrm{o}}(g)$ from the expression in (27). The position of the rotary spring is then modified according to (1) to match the required natural frequency. This procedure is iteratively carried out until the machining becomes stable or when a limit of six iterations is reached, if the process cannot be stabilized at all.

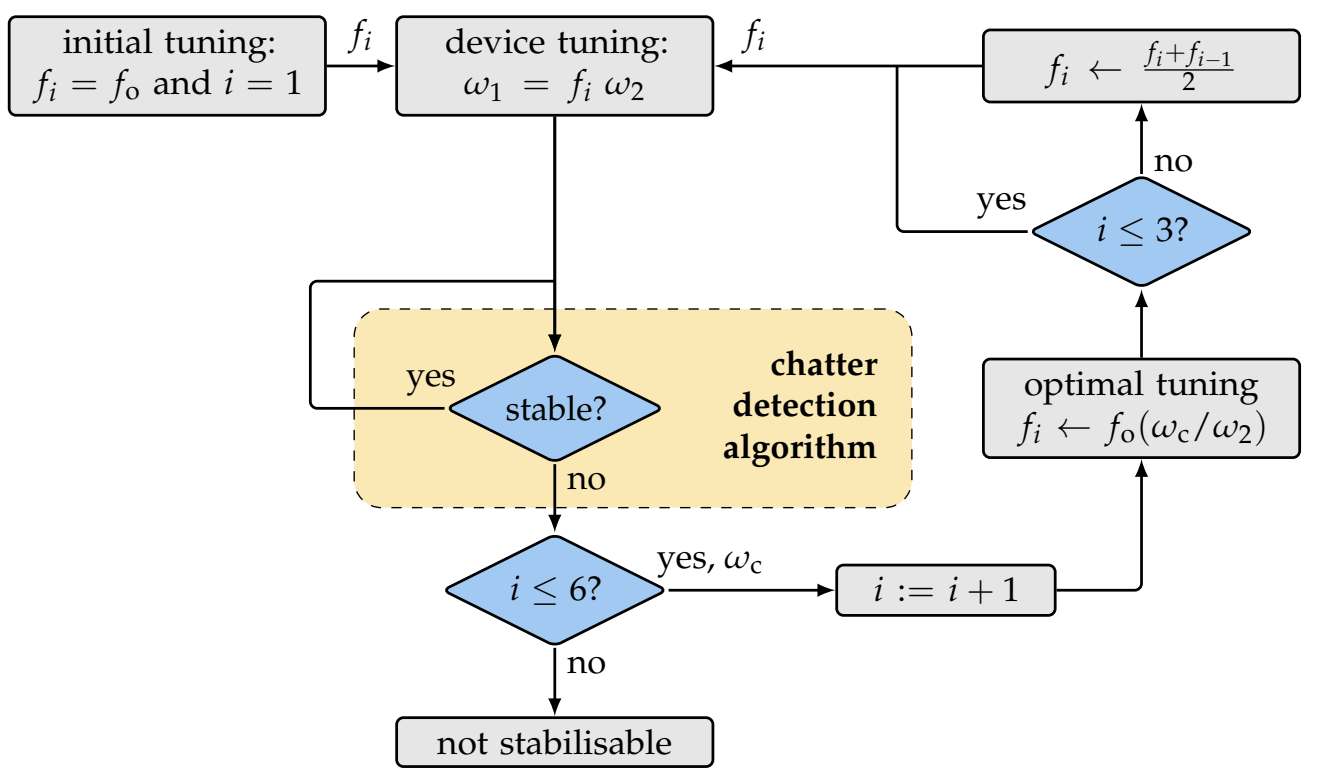

Figure 7. Implemented algorithm for chatterless blade recontouring based on the real-time measured chatter frequency.

However, under certain cutting parameters, the tuning may oscillate and not converge to its optimal value even for a theoretically stabilizable point, as the changes on the assembly dynamics produced by the tuning lead to too large chatter frequency jumps. In these instances, the convergence of the algorithm can be improved as follows: after a threshold of three tuning iterations, the ideal objective tuning is calculated with the expression in (27), but in spite of directly tuning the device to that value, the device is tuned to the mean value of the actual tuning and the calculated ideal tuning, achieving a better convergence.

\section{Validation of the Concept}

The introduced self-tuning algorithm has theoretically demonstrated a higher performance compared to other wide-bandwidth tuning methods. It has been noted that ZOA leads to accurate stability predictions as long as the milling process is not interrupted or only lightly interrupted. Nonetheless, blade recontouring may involve low radial immersion operations performed with cutters featuring few teeth and negligible smoothing effect of the tool helix. This would lead to an interrupted cutting that could favour the occurrence of both flip instabilities and machining mode coupling effects that might compromise the effectiveness of the algorithm. For this reason, the effectiveness of the algorithm presented in this paper is validated in this section by means of the semidiscretization and initial value time domain simulations for the milling case in Table 2, which resembles an interrupted recontouring operation. 
Table 2. Definition of the dimensionless dynamic and tuning parameters of the structure.

\begin{tabular}{cccccccc}
\hline \multicolumn{9}{c}{ Tool/Material } & \multicolumn{3}{c}{ Process } \\
\hline$D(\mathrm{~mm})$ & $\mathrm{Z}$ & $\mathbf{K}_{\mathrm{c}}(\mathrm{MPa})$ & $\mathbf{K}_{\mathrm{e}}(\mathrm{N} / \mathrm{mm})$ & immersion $(\%)$ & strategy & $\beta_{0}$ & $f_{Z}(\mathrm{~mm})$ \\
\hline 12 & 3 & {$[800,320]^{\top}$} & {$[30,40]^{\top}$} & 25 & down-milling & 0.67 & 0.1 \\
\hline \multicolumn{1}{c}{ Part Dynamics } & & & TCT & \\
\hline$\omega_{2}(\mathrm{~Hz})$ & $\zeta_{2}(\%)$ & $m_{2}(\mathrm{~kg})$ & $\mu(\%)$ & $m_{1}$ & $\zeta_{1}=\zeta_{1, \mathrm{o},+}(\%)$ & {$\left[f_{\min }, f_{\max }\right]$} \\
\hline 300 & 0.5 & 0.5 & 5 & 10 & $12.2 \%$ & {$[0.5,2]$} \\
\hline
\end{tabular}

\subsection{Milling Stability through Semidiscretization Method}

The stability and chatter frequency charts for the standalone (stiff) clamping, the TCT under broad-bandwidth tuning and the self-tuned TCT obtained through semidiscretization [43] are respectively shown in Figure 8a,b. For the self-tuned case, the chatter frequency is computed for every unstable point of the $\Omega-a$ mesh as in [49], and optimal tuning is iteratively performed according to the algorithm in Figure 7 until the process is stable or a maximum of 6 iterations is reached.

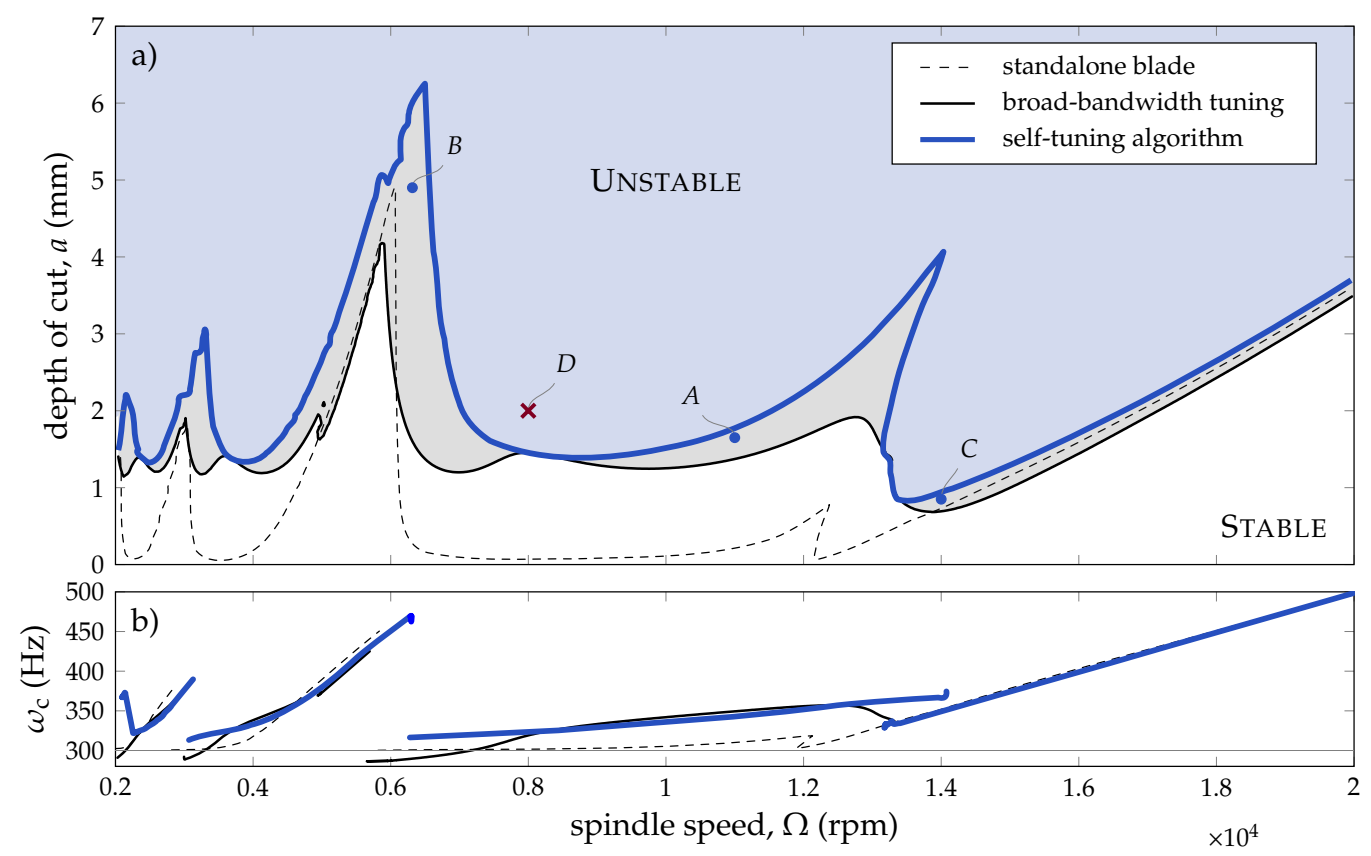

Figure 8. Results of the semidiscretization calculations for the milling case in Table 2 with standalone (stiff) clamping, TCT under broad-bandwidth tuning and TCT under self-tuning algorithm. (a) Stability lobe limit diagrams. (b) Chatter frequency diagrams.

The results from the semidiscretization calculations confirm the superior performance of the iterative strategy over the fixed-frequency strategy, with the exceptions of the aforementioned spindle speeds at which the two strategies converge. Moreover, it can also be noticed that the introduced strategy also increases the stability limit for spindle speed ranges where a dominant period doubling behavior may be expected, even if the expressions driving their stability limit differ from those of the Hopf-kind instabilities [50]. 


\subsection{Initial Value Time Domain Simulations with Fly-Over Effect}

So far, an ideal linear milling model has been considered in order to devise the tuning algorithm and validate it through semidiscretization calculations. However, the real milling cases are subdued to the fly-over non-smoothness [51], effect by which the cutting edge jumps out of the cut due to the vibration. Apart from being the cause of the vibration amplitude reaching a threshold instead of growing indefinitely, this strong non-linearity also induces a multi-regenerative effect than can make the chatter frequencies diverge from the ideal linear case [52] and, thus, compromise the effectiveness of the tuning strategy.

In order to assess the robustness of the self-tuning algorithm against these deviations, initial value time domain simulations of (2) have been performed together with the selftuning algorithm. With this purpose, (2) is transformed onto its modal state-space form and numerically solved through an exponential time differencing forward Euler scheme [53]. For each discrete time step, the cutting force in (7) is calculated by considering a total of 20 prior tooth passes for the computation of the chip thickness and switching it off whenever fly-over takes place $\left(h_{i}(t)<0\right)$.

For each $\Omega, a$ point, the chatter detection algorithm is run every 100 tool rotation periods, of which the last 60 periods are taken for the FFT calculation. Chatter is detected and its dominant frequency $\omega_{\mathrm{c}}$ measured if any peak is noticed at frequencies not matching the tooth passing frequency $\omega_{Z}$ and if its amplitude is higher than the $30 \%$ of the largest tooth passing harmonic. If this is the case, the tuning of the device $\omega_{1}$ is computed according to Figure 7 based on the measured chatter frequency $\omega_{c}$, and the system matrices corresponding to the new tuning $k_{1}=m_{1} \omega_{1}^{2}$ are recalculated. Here, it is considered that the tuning mechanism (rotary spring) is agile enough to perform the system retuning without affecting the system stability. Therefore, the dynamics of the tuning mechanism are omitted and the tuning is assumed to take place instantaneously. The process is iteratively repeated until the stability is reached or the tuning goes into an oscillatory situation (machining stability is not possible).

The results of the time domain simulations for the A, B, C and D points from the stability chart in Figure 8 are shown in Figure 9. As predicted by the semidiscretization calculations, the algorithm successfully stabilizes the initially Hopf unstable cases. Point B (see Figure 9b), chosen according to the stability asymptote in Figure $6 c$, confirms that large stability gains can be attained with the TCT by integrating the self-tuning algorithm and adjusting the spindle speed to the stability asymptote. The capacity of the algorithm to enhance the stability in period doubling zones is also demonstrated in Figure 9c, as one case of flip chatter was successfully suppressed by the tuning algorithm. An 'unstabilizable' case can be seen in Figure 9d, where an oscillatory behavior between two unstable tunings is reached.

Finally, once the capability of the algorithm to maximize the stability of the system has been demonstrated, it would also be important to study the robustness aspects of the algorithm itself. One of the main hazards for all the mode tuning strategies is the uncertainty with respect to the actual dynamic parameters of the system, namely, initial deviations of the part dynamics or deviations due to the material removal. In this sense, an in-depth analysis of the uncertainty and variability of the system parameters and their effect on the tuning robustness would be decisive for a proper design of devices based on the TCT architecture. 

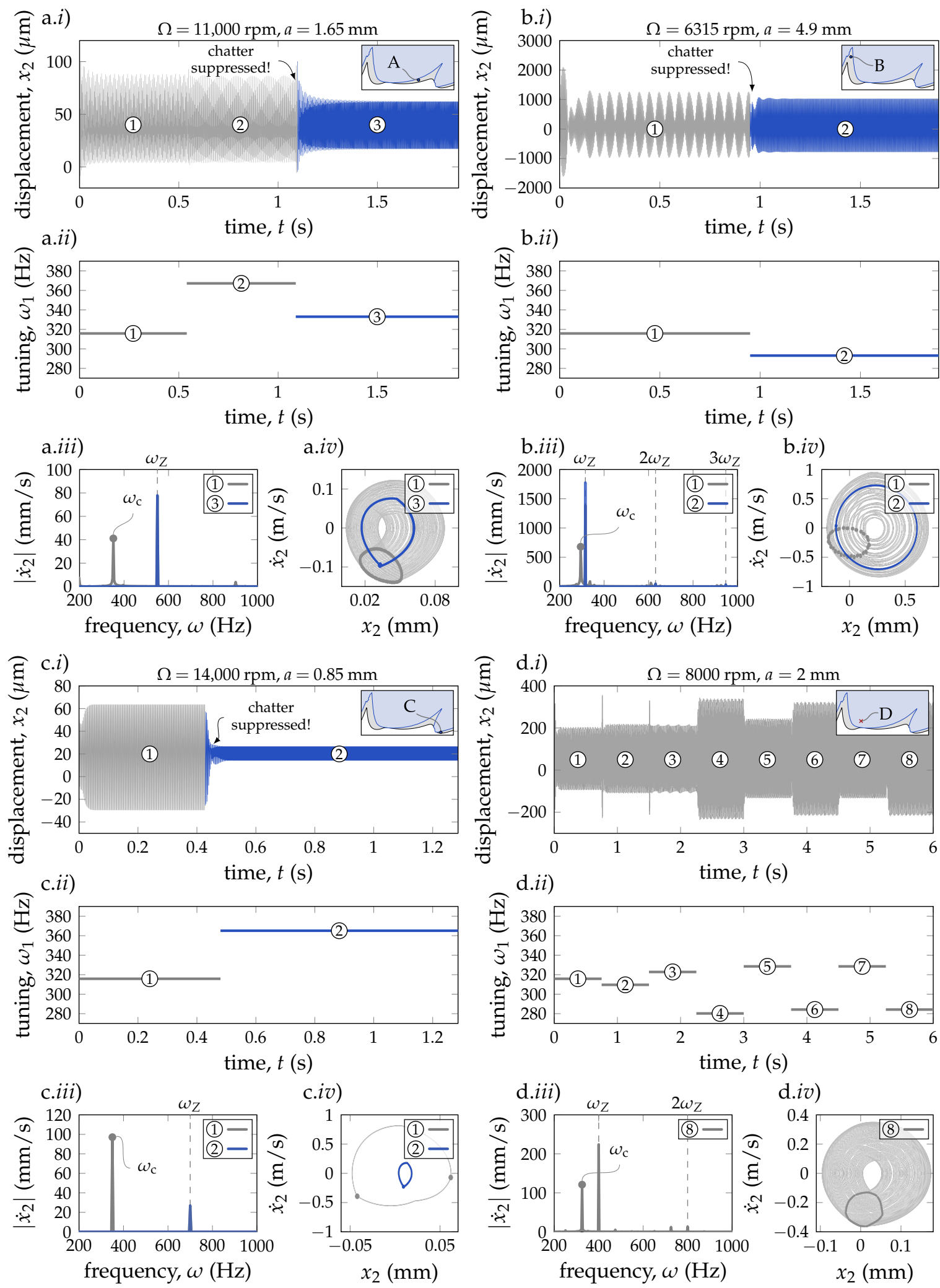

\section{chatter - stable (1), (2), (i) tuning iteration}

Figure 9. Results of the initial value time domain simulations with fly-over effect for the milling case in Table 2. (i) Blade tip displacement $x_{2}$. (ii) standalone TCT tuning frequency $\omega_{1}$. (iii) Frequency spectrum of the blade tip displacement velocity $\left|\dot{x}_{2}\right|$. (iv) Phase and Poincaré diagrams. 


\section{Conclusions}

The wide variety of different blade geometries present in a single engine makes blade manufacturing and repairing processes a complex task, since specific stiffening fixtures are needed for each geometry in order to avoid machining chatter when performing the recontouring operations. Similarly to TMDs, the tuneable clamping table can damp the critical modes by means of mode tuning, but thanks to its in-series configuration, the tuning can be achieved without interfering with the cutting area, enabling a more universal clamping. Aiming at maximising its chatter suppression capabilities, a selftuning algorithm has been developed for TCT architecture. The algorithm iteratively measures the frequency of the arising chatter and optimally tunes the device for that frequency, outperforming other wide-bandwidth tuning strategies. The effectiveness of the algorithm has been validated through semidiscretization calculations and initial value time domain simulations, where the stability enhancement provided in the ideal linear case has been validated. The industrial application of the algorithm would require studying the robustness of the algorithm with respect the uncertainty of the part dynamics due to initial deviations or material removal.

Author Contributions: Conceptualization: M.S.-C., Z.D. and J.M.; software: M.S.-C. and Z.D.; investigation: M.S.-C., writing — original draft preparation: M.S.-C.; writing—review and editing: Z.D. and A.I.; supervision: J.M. and L.N.L.d.L. All authors have read and agreed to the published version of the manuscript.

Funding: This project has been funded by the MIRAGED: Posicionamiento Estratégico en Modelos Virtuales y Gemelos Digitales para una Industria 4.0 (CER-20191001), supported by CDTIAcreditación y Concesión de Ayudas Destinadas a Centros Tecnológicos de Excelencia Cervera; the Hungarian NKFI FK 124361 and the TiMachina project (IDI-201904196) from the International Technological Corporation, and by $\mathrm{R}+\mathrm{d}$ projects program of the Spanish Centre for the Development of Industrial Technology (CDTI).

Institutional Review Board Statement: Not applicable.

Informed Consent Statement: Not applicable.

Data Availability Statement: Not applicable.

Acknowledgments: This research work has been done under the framework of the project MIRAGED: Posicionamiento Estratégico en Modelos Virtuales y Gemelos Digitales para una Industria 4.0 (CER-20191001), supported by CDTI-Acreditación y Concesión de Ayudas Destinadas a Centros Tecnológicos de Excelencia Cervera; the Hungarian NKFI FK 124361 and the TiMachina project (IDI-201904196) from the International Technological Corporation, and by $\mathrm{R}+\mathrm{d}$ projects program of the Spanish Centre for the Development of Industrial Technology (CDTI).

Conflicts of Interest: The authors declare no conflict of interest.

\section{Abbreviations}

The following abbreviations are used in this manuscript:

DDE delay differential equation

FFT fast Fourier transform

MRO maintenance, repair and overhaul

SLD stability lobe diagram

TMD tuned mass damper

TCT tuneable clamping table

ZOA zeroth order algorithm 


\section{Nomenclature}

\begin{tabular}{|c|c|}
\hline$(t, r)$ & $\mathrm{t}$ : tangential, r: radial \\
\hline $\mathbf{M}$ & assembly mass matrix \\
\hline $\mathrm{C}$ & assembly viscous damping matrix \\
\hline K & assembly stiffness matrix \\
\hline $\mathbf{H}$ & assembly receptance matrix \\
\hline$m_{i}$ & modal (reflected) mass of the $i$ th substructure \\
\hline$k_{i}$ & modal (reflected) stiffness of the $i$ th substructure \\
\hline$k_{\mathrm{f}}$ & flexure stiffness \\
\hline$k_{\mathrm{s}}$ & rotary spring stiffness \\
\hline$c_{i}$ & modal (reflected) viscous damping of the $i$ th substructure \\
\hline$H_{i, j}$ & receptance function between the $i$ th and $j$ th substructures \\
\hline$\theta$ & angular position of the rotary spring \\
\hline $\mathbf{x}$ & displacement vector \\
\hline $\mathbf{x}_{\mathrm{S}}$ & stationary solution vector \\
\hline p & perturbed solution vector \\
\hline $\mathbf{F}$ & force vector \\
\hline $\mathbf{f}_{t r}$ & specific cutting force in tangential-radial $(t, r)$ coordinates \\
\hline $\mathbf{K}_{\mathrm{c}}$ & cutting coefficient vector \\
\hline $\mathbf{K}_{\mathrm{e}}$ & edge coefficient vector \\
\hline$f_{Z}$ & feed per tooth \\
\hline$\Omega$ & spindle speed \\
\hline$a$ & axial depth of cut \\
\hline$h$ & chip thickness \\
\hline$\varphi_{\mathrm{en}}$ & entering immersion angle \\
\hline$\varphi_{\mathrm{ex}}$ & exit immersion angle \\
\hline$\varphi$ & angular position of the cutter \\
\hline$\tau$ & regenerative delay \\
\hline$T_{Z}$ & tooth passing period \\
\hline$\omega_{Z}$ & tooth passing frequency \\
\hline$\omega_{\mathrm{c}}$ & dominant chatter frequency \\
\hline$\psi_{i, j}$ & phase of the receptance between the $i$ th and $j$ th substructures \\
\hline$\omega$ & excitation frequency \\
\hline$g(\varphi)$ & screen function \\
\hline$g$ & dimensionless excitation frequency \\
\hline$\mu$ & mass ratio \\
\hline$\zeta_{i}$ & standalone damping ratio of the $i$ th substructure \\
\hline$\omega_{i}$ & standalone natural frequency of the $i$ th substructure \\
\hline$f$ & frequency ratio \\
\hline$h_{i, j}(g)$ & dimensionless receptance between the $i$ th and $j$ th substructures \\
\hline$f_{\mathrm{O}, \pm}$ & optimal frequency tuning ratio of the broad-bandwidth strategy \\
\hline$\zeta_{1,0, \pm}$ & optimal TCT damping ratio of the broad-bandwidth strategy \\
\hline$f_{\operatorname{Re} h_{22}=0}$ & zero real part tuning ratio \\
\hline$f_{\frac{\mathrm{d} \operatorname{Re} h_{22}}{\mathrm{~d} f}=0, \pm}$ & zero real part derivative tuning ratio \\
\hline$f_{\mathrm{o}}(g)$ & optimal frequency tuning ratio of the excitation frequency dependent strategy \\
\hline$g_{\lim , \pm}$ & dimensionless TCT tuning limits \\
\hline$f_{\max }$ & upper tuning ratio limit \\
\hline$f_{\min }$ & lower tuning ratio limit \\
\hline$g_{\mathrm{a}}$ & dimensionless frequency of the stability asymptote \\
\hline$v_{\mathrm{a}}$ & dimensionless spindle speed of the stability asymptote \\
\hline$v$ & dimensionless spindle speed \\
\hline$\sigma$ & dimensionless depth of cut \\
\hline$B$ & directional milling coefficient \\
\hline$\beta$ & directional factor \\
\hline$\Delta F$ & regenerative milling force \\
\hline G & stationary milling force \\
\hline Z & number of flutes of the cutter \\
\hline$D$ & cutter diameter \\
\hline
\end{tabular}




\section{References}

1. Yilmaz, O.; Noble, D.; Gindy, N.N.; Gao, J. A study of turbomachinery components machining and repairing methodologies. Aircr. Eng. Aerosp. Technol. 2005, 77, 455-466. [CrossRef]

2. Denkena, B.; Boess, V.; Nespor, D.; Floeter, F.; Rust, F. Engine blade regeneration: A literature review on common technologies in terms of machining. Int. J. Adv. Manuf. Technol. 2015, 81, 917-924. [CrossRef]

3. Bieler, H. Einkristalle Reparieren; Technical Report; Sulzer AG: Winterthur, Switzerland, 1997.

4. Yilmaz, O.; Gindy, N.; Gao, J. A repair and overhaul methodology for aeroengine components. Robot. Comput.-Integr. Manuf. 2010, 26, 190-201. [CrossRef]

5. Penaranda, X.; Moralejo, S.; Lamikiz, A.; Figueras, J. An adaptive laser cladding methodology for blade tip repair. Int. J. Adv. Manuf. Technol. 2017, 92, 4337-4343. [CrossRef]

6. Burbaum, B.; Kamel, A.; Bostanjoglo, G.; Ott, M.; Stöhr, B.; Ahmad, F. Maintenance, Repair and Overhaul of Gas Turbine Components for Lifetime Extension Maintenance, Repair and Overhaul of Gas Turbine Components Content; Siemens: Aachen, Germany, 2019.

7. Bremer, C. AROSATEC (Automated Repair and Overhaul System for Aero Turbine Engine Components) Final Report; Technical Report; BCT GmbH: Dortmund, Germany, 2006.

8. Brecher, C.; Klocke, F.; Breitbach, T.; Do-Khac, D.; Heinen, D.; Karlberger, A.; Rosen, C.J. A hybrid machining center for enabling new die manufacturing and repair concepts. Prod. Eng. 2011, 5, 405-413. [CrossRef]

9. Tobias, S.A.S.; Fishwick, W. Theory of Regenerative Machine Tool Chatter. Engineer 1958, 205, $199-203$.

10. Tlusty, J.; Polacek, M. The stability of machine tools against self-excited vibrations in machining. ASME Int. Res. Prod. Eng. 1963, 1, 465-474.

11. Munoa, J.; Beudaert, X.; Dombovari, Z.; Altintas, Y.; Budak, E.; Brecher, C.; Stepan, G. Chatter suppression techniques in metal cutting. CIRP Ann.-Manuf. Technol. 2016, 65, 785-808. [CrossRef]

12. Stepan, G.; Hajdu, D.; Iglesias, A.; Takacs, D.; Dombovari, Z. Ultimate capability of variable pitch milling cutters. CIRP Ann. 2018, 67, 373-376. [CrossRef]

13. Bediaga, I.; Egaña, I.; Muñoa, J. Reducción de la Inestabilidad en Cortes Interrumpidos en Fresado a Alta Velocidad mediante Variación de la Velocidad del Husillo. In Proceedings of the XVI Congreso de Máquinas-Herramienta y Tecnologías de Fabricación, San Sebastián, Spain, 18-20 October 2006.

14. Mörhring, H.C. Messtechnische Analyse formflexibler Spannmethoden. Werkstattstechnik 2012, 102, 795-800.

15. Beudaert, X.; Erkorkmaz, K.; Munoa, J. Portable damping system for chatter suppression on flexible workpieces. CIRP Ann. 2019, 68, 423-426. [CrossRef]

16. Kolluru, K.; Axinte, D. Coupled interaction of dynamic responses of tool and workpiece in thin wall milling. J. Mater. Process. Technol. 2013, 213, 1565-1574. [CrossRef]

17. Gubanov, G. Broadband pneumatic mass damper for the elimination of workpiece vibrations. CIRP J. Manuf. Sci. Technol. 2020. [CrossRef]

18. Munoa, J.; Sanz-Calle, M.; Dombovari, Z.; Iglesias, A.; Pena-Barrio, J.; Stepan, G. Tuneable clamping table for chatter avoidance in thin-walled part milling. CIRP Ann. 2020, 14-17. [CrossRef]

19. Ormondroyd, J.; Den Hartog, J. The theory of the dynamic vibration absorber. J. Appl. Mech. 1928, 50, 9-22.

20. Den Hartog, J.P. Mechanical Vibrations; McGraw-Hill: New York, NY, USA, 1947.

21. Koenigsberger, F.; Tlusty, J. Machine Tool Structures; Pergamon Press: Oxford, UK,1970; Volume 1. [CrossRef]

22. Sims, N.D. Vibration absorbers for chatter suppression: A new analytical tuning methodology. J. Sound Vib. 2007, 301, 592-607. [CrossRef]

23. Pena-Barrio, J.; Sanz-Calle, M.; Aguirre, G.; Iglesias, A.; Stepan, G.; López De Lacalle, L.N. Optimal tuning strategy for chatter avoidance in thin- walled part milling by means of tuneable clamping table. In Proceedings of the ISMA2020 and USD2020, Leuven, Belgium, 7-9 September 2020; pp. 3119-3132.

24. Slavicek, J.; Bollinger, J. Design and Application of a Self-Optimizing Damper for Increasing Machine Tool Performance. In Advances in Machine Tool Design and Research; Pergamon Press Ltd.: Oxford, UK, 1969; pp. 71-81. [CrossRef]

25. Seto, K.; Tominari, N. Effect of a Variable Stiffness-Type Dynamic Damper on Machine Tools with Long Overhung Ram. CIRP Ann. 1978, 27, 327-332. [CrossRef]

26. Yuan, L.; Sun, S.; Pan, Z.; Ding, D.; Gienke, O.; Li, W. Mode coupling chatter suppression for robotic machining using semi-active magnetorheological elastomers absorber. Mech. Syst. Signal Process. 2019, 117, 221-237. [CrossRef]

27. Olarra, A.; Azpeitia, J.L.; Guruceta, E.; Sánchez, M.; Cantero, C. Aplicación de Absorbedores Dinámicos Sintonizados en Máquina Herramienta. In Proceedings of the XVIII Congreso de Máquinas-Herramienta y Tecnologías de Fabricación, San Sebastián, Spain, 10-12 November 2010.

28. Aguirre, G.; Gorostiaga, M.; Porchez, T.; Muñoa, J. Self-tuning semi-active tuned-mass damper for machine tool chatter suppression. ISMA2012-USD2012 2012, 1, 109-123.

29. Munoa, J.; Iglesias, A.; Olarra, A.; Dombovari, Z.; Zatarain, M.; Stepan, G. Design of self-tuneable mass damper for modular fixturing systems. CIRP Ann.-Manuf. Technol. 2016, 65, 389-392. [CrossRef]

30. Yang, Y.; Xie, R.; Liu, Q. Design of a passive damper with tunable stiffness and its application in thin-walled part milling. Int. J. Adv. Manuf. Technol. 2017, 89, 2713-2720. [CrossRef] 
31. Sims, N.; Stanway, R.; Johnson, A. Vibration control using smart fluids: A state-of-the-art review. Shock Vib. Dig. 1999, 31, 195-203. [CrossRef]

32. Díaz-Tena, E.; López de Lacalle, L.N.; Ampa, F.J.; Bocanegra, D.L.C. Use of Magnetorheological Fluids for Vibration Reduction on the Milling of Thin Floor Parts. Procedia Eng. 2013, 63, 835-842. [CrossRef]

33. Ma, J.; Zhang, D.; Wu, B.; Luo, M.; Liu, Y. Stability improvement and vibration suppression of the thin-walled workpiece in milling process via magnetorheological fluid flexible fixture. Int. J. Adv. Manuf. Technol. 2017, 88, 1231-1242. [CrossRef]

34. Moheimani, S.O.R.; Fleming, A.J. Piezoelectric Transducers for Vibration Control and Damping (Advances in Industrial Control); Springer Science \& Business Media: Berlin, Germany, 2006; p. 271.

35. Venter, G.S.; Silva, L.M.d.P.; Carneiro, M.B.; da Silva, M.M. Passive and active strategies using embedded piezoelectric layers to improve the stability limit in turning/boring operations. Int. J. Adv. Manuf. Technol. 2017, 89, 2789-2801. [CrossRef]

36. Yigit, U.; Cigeroglu, E.; Budak, E. Chatter reduction in boring process by using piezoelectric shunt damping with experimental verification. Mech. Syst. Signal Process. 2017, 94, 312-321. [CrossRef]

37. Sims, N.D.; Stanway, R.; Peel, D.J.; Bullough, W.A.; Johnson, A.R. Controllable viscous damping: An experimental study of an electrorheological long-stroke damper under proportional feedback control. Smart Mater. Struct. 1999, 8, 601-615. [CrossRef]

38. Wang, M.; Fei, R. Chatter suppression based on nonlinear vibration characteristic of electrorheological fluids. Int. J. Mach. Tools Manuf. 1999, 39, 1925-1934. [CrossRef]

39. Sajedi Pour, D.; Behbahani, S. Semi-active fuzzy control of machine tool chatter vibration using smart MR dampers. Int. J. Adv. Manuf. Technol. 2016, 83, 421-428. [CrossRef]

40. Munoa, J.; Dombovari, Z.; Iglesias, A.; Stepan, G.; Stepan Tuneable, G.; Iglesias, A. Tuneable mass dampers with variable stiffness for chatter suppression mass dampers with variable stiffness for chatter suppression. In Proceedings of the 4th International Conference on Virtual Machining Process Technology (VMPT 2015), Vancouver, BC, Canada, 2-5 June 2015.

41. Altintas, Y. Manufacturing Automation: Metal Cutting Mechanics, Machine Tool Vibrations, and CNC Design, 2nd ed.; Cambridge University Press: Cambridge, UK, 2012. [CrossRef]

42. Stepan, G. Retarded Dynamical Systems: Stability and Characteristic Functions; Longman: Harlow, UK, 1989 ; p. 159.

43. Insperger, T.; Stepan, G. Semi-Discretization for Time-Delay Systems; Springer Science \& Business Media: Berlin, Germany, 2011; p. 185.

44. Ding, Y.; Zhu, L.M.; Zhang, X.J.; Ding, H. A full-discretization method for prediction of milling stability. Int. J. Mach. Tools Manuf. 2010, 50, 502-509. [CrossRef]

45. Opitz, H.; Bernardi, F. Investigation and Calculation of the Chatter Behaviour of Lathes and Milling Machines. CIRP Ann. 1970, 18, 335-343. [CrossRef]

46. Altintas, Y.; Budak, E. Analytical Prediction of Stability Lobes in Milling. CIRP Ann. 1995, 44, 357-362. [CrossRef]

47. Munoa, J.; Dombovari, Z.; Mancisidor, I.; Yang, Y.; Zatarain, M. Interaction between multiple modes in milling processes. Mach. Sci. Technol. 2013, 17, 165-180. [CrossRef]

48. Farkas, M. Periodic Motions; Springer: Berlin/Heidelberg, Germany, 1994; p. 3. [CrossRef]

49. Dombovari, Z.; Iglesias, A.; Zatarain, M.; Insperger, T. Prediction of multiple dominant chatter frequencies in milling processes. Int. J. Mach. Tools Manuf. 2011, 51, 457-464. [CrossRef]

50. Iglesias, A.; Munoa, J.; Ciurana, J.; Dombovari, Z.; Stepan, G. Analytical expressions for chatter analysis in milling operations with one dominant mode. J. Sound Vib. 2016, 375, 403-421. [CrossRef]

51. Tlusty, J.; Ismail, F. Basic Non-Linearity in Machining Chatter. CIRP Ann. 1981, 30, 299-304. [CrossRef]

52. Kondo, Y.; Kawano, O.; Sato, H. Behavior of Self-Excited Chatter Due To Multiple Regenerative Effect. J. Eng. Ind. 1981, 103, 324-329. [CrossRef]

53. Cox, S.M.; Matthews, P.C. Exponential Time Differencing for Stiff Systems. J. Comput. Phys. 2002, 455, 430-455. [CrossRef] 